\title{
Redo in Thyroid Surgeries
}

Mohamed Fathalla El Ghandour*, Tamer Youssef Mohamed, Yasser Ali Elsayed, Mohamed Saber Mohamed Amin

Endocrine Surgery Unit, Faculty of Medicine, Mansoura University, Egypt

*Corresponding author: Mohamed Fathalla El Ghandour, Mobile: 01001556413, E-mail: Mohamedghadour22@gmail.com

\begin{abstract}
Background: Revision of thyroid surgery is usually technically difficult because of anatomical changes and subsequent fibrosis after the primary surgery especially in the central neck. However, with experience and appropriate preparation, the risk of permanent hypoparathyroidism or recurrent laryngeal nerve injury after revision surgery is reduced. Objective: The aim of the study was to determine the causes of redo in thyroid surgeries, operative difficulties and postoperative complications.

Patients and Methods: This prospective randomized controlled study included a total of 60 patients with primary total thyroidectomy and redo surgery, attending at Endocrine Surgery Unit, General Surgery Department, and Mansoura University Hospitals. This study was conducted between February 2018 and January 2019. The included subjects were randomly divided into three main groups: Group 1 (primary total thyroidectomy) consisted of 20 patients underwent total thyroidectomy, Group 2 (early redo surgery) consisted of 20 patients underwent completion thyroidectomy, and Group 3 (late redo surgery) consisted of 20 patients underwent recurrent thyroidectomy.

Results: Compared to total thyroidectomy, early and late redo in thyroid surgeries gave better results regarding the recurrence and complications, which occurred in no one case 1 year later.

Conclusion: From this study it is shown that total thyroidectomy is advised to be done in all patients with thyroid diseases as there were no recurrence detected and to avoid complications that may be present in redo surgery. To guard against performance of completion thyroidectomy, ultrasound examination and fine needle aspiration cytology (FNAC) should be taken from different sites.
\end{abstract}

Keywords: Complications, Redo in thyroid surgeries.

\section{INTRODUCTION}

Recurrent thyroid disease is less common to be seen. When recurrence occurs; it represents a significant clinical and surgical challenge. The complication rates of recurrent laryngeal nerve injury and hypoparathyroidism with revision surgery are higher than at an initial operation. Palpable recurrence of nontoxic nodular goiter is documented to occur in $0.3 \%$ to $42 \%$ of patients who have had previous surgery for the same condition ${ }^{(\mathbf{1})}$.

Tumor recurrence is more common in differentiated thyroid cancer than benign in thyroid disease, most are diagnosed within 10 years of initial treatment of differentiated thyroid cancer ${ }^{(2)}$. Revision of thyroid surgery is usually technically difficult because of anatomical changes and subsequent fibrosis after the primary surgery especially in the central neck (3). However, with experience and appropriate preparation, the risk of permanent hypoparathyroidism or recurrent laryngeal nerve injury after revision surgery is reduced ${ }^{(4)}$.

Therefore, surgeons must be intimately familiar with the distorted anatomy present at re-exploration in an attempt to reduce the incidence of these complications ${ }^{(5)}$.

The aim of the current study was to determine the causes of redo in thyroid surgeries, operative difficulties and postoperative complications.

\section{PATIENTS AND METHODS}

This prospective randomized controlled study included a total of 60 patients with redo in thyroid surgeries, attending at Endocrine Surgery Unit, General Surgery Department, and Mansoura University Hospitals (MUH). This study was conducted between February 2018 and January 2019.

\section{Ethical consent:}

An approval of the study was obtained from Mansoura University Academic and Ethical Committee. Every patient signed an informed written consent for acceptance of the operation and sharing in the study. This work has been carried out in accordance with The Code of Ethics of the World Medical Association (Declaration of Helsinki) for studies involving humans.

Sample size was calculated using G- Power with effect size 0.8 and power of 0.8 and it was 60 patients The included subjects were randomly divided into 3 groups: Group 1 (primary total thyroidectomy) consisted of 20 patients underwent total thyroidectomy, Group 2 (early redo surgery) consisted of 20 patients underwent completion thyroidectomy, and Group 3 (late redo surgery) consisted of 20 patients underwent recurrent thyroidectomy 


\section{Inclusion criteria:}

Patients with total thyroidectomy, early and late redo surgery, both genders and age was between 31 and 69 .

\section{Exclusion criteria:}

Patients with recurrent congenital or inflammatory thyroid disease, patients with vocal cord problems, and patients with metastatic thyroid carcinoma.

\section{All patients were subjected to the following:}

A) History: Detailed history taking from each patient regarding age, with special reference to present, past, medical history.

B) General, body built, look of patients, decubitus, mental state, vital signs (sleeping pulse, blood pressure and temperature), facial expression, upper and lower limbs, chest, heart, abdomen and skeletal examinations.

C) Examination of the thyroid was done including: inspection, palpation, percussion and auscultation, Comment on thyroid swelling: Site, side, size, shape, surface, overlying skin, E.N.T examination and assessment of vocal cords mobility (all patients should have negative results).
D) Thyroid function tests (Serum T3, T4 and TSH). Complete Laboratory tests, E.C.G, Neck ultrasound (U/S), Preoperative FNAC, Postoperative pathology.

\section{Thyroidectomy technique:}

Total thyroidectomy was performed by extra capsular dissection to remove both thyroid and pyramidal lobes. We preferred to identify the nerve just caudal to the point where it crosses the inferior thyroid artery and to dissect it in both directions: caudally to the mediastinum and cranially to the cricothyroid junction.

After the thyroid gland was mobilized medially, the connective tissue on the tracheoesophageal space was dissected to identify the nerve. If the nerve bifurcates in branches, which is not a rare condition, all of the branches were identified.

All vessels were ligated close to the thyroid gland especially the branches of the inferior thyroid artery. Parathyroid glands and recurrent laryngeal nerves (RLNs) were observed and preserved in a similar way, lobectomy was performed on the larger or the more nodular thyroid lobe or including the dominant nodule with contralateral subtotal resection leaving an average of 1-2 gm. of thyroid tissue. Non-viable parathyroid glands were auto transplanted immediately.

\section{Sample of cases:}
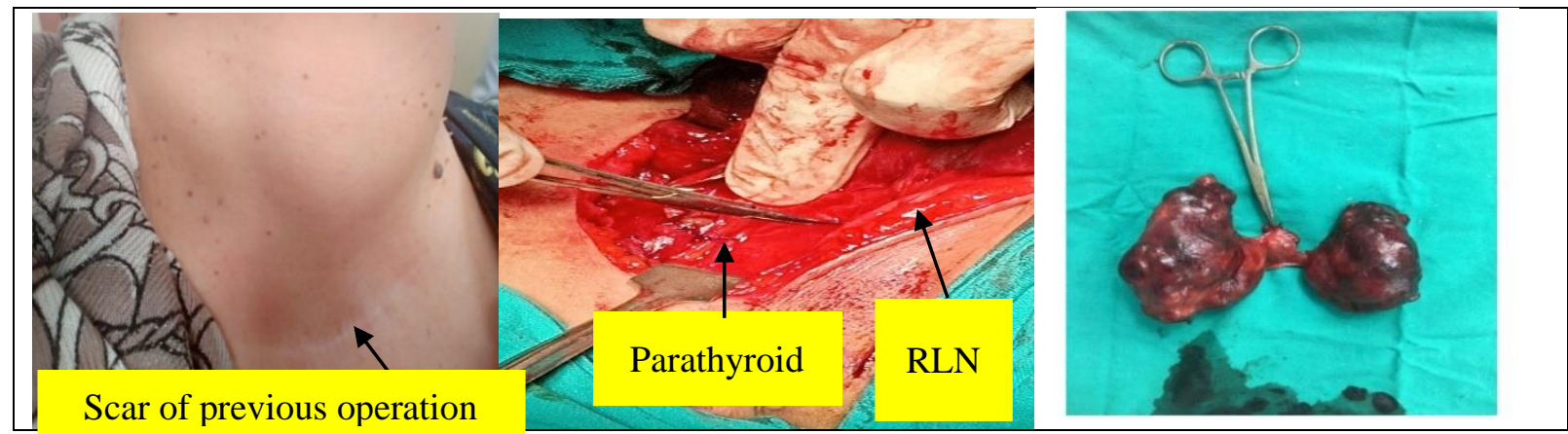

Case (1): Shows 45-year-old female patient with recurrence after subtotal thyroidectomy underwent recurrent thyroidectomy (late redo surgery). Bed of the removed thyroid gland showing 1 . Recurrent laryngeal nerve (RLN) 2. Parathyroid Glands "PGs" 3. Remnant of thyroid tissue, Removed specimen after recurrent thyroidectomy.

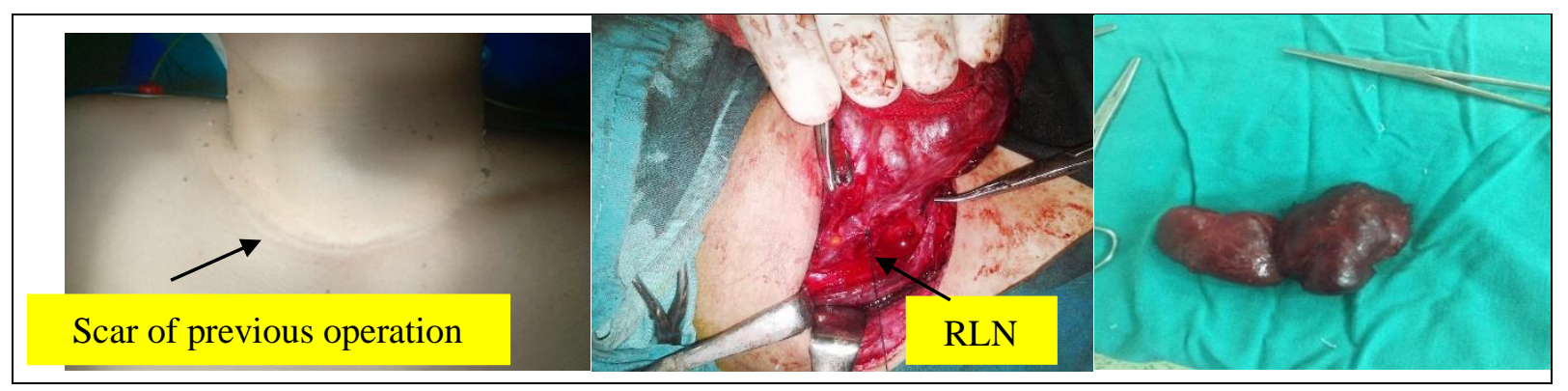

Case (2): Shows 37-year-old female patient with recurrent Toxic goiter underwent recurrent thyroidectomy late redo surgery. Bed of the removed thyroid gland showing 1. Recurrent laryngeal nerve (RLN) 2. Parathyroid glands (PGs), Removed specimen late redo thyroidectomy. 


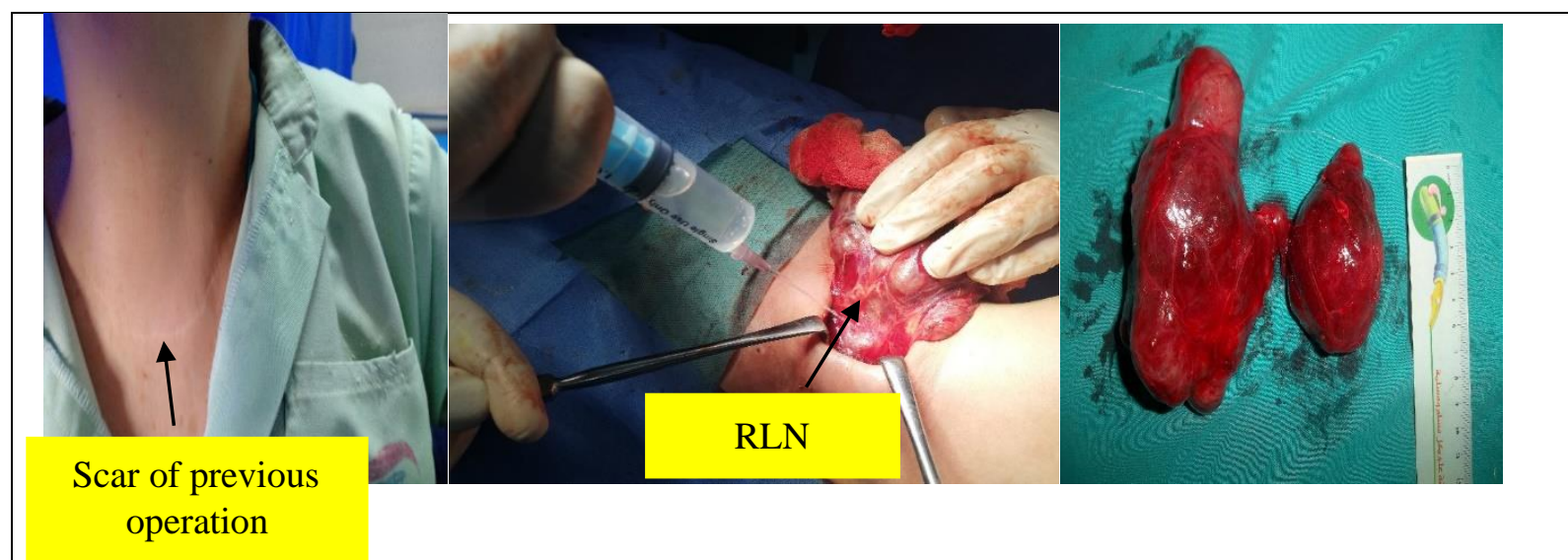

Case (3): Shows 42-year-old female patient with recurrent toxic goiter underwent recurrent thyroidectomy late redo surgery. Bed of the removed thyroid gland showing 1. Recurrent laryngeal nerve (RLN) 2. Parathyroid Glands (PGs), Removed specimen late redo thyroidectomy.

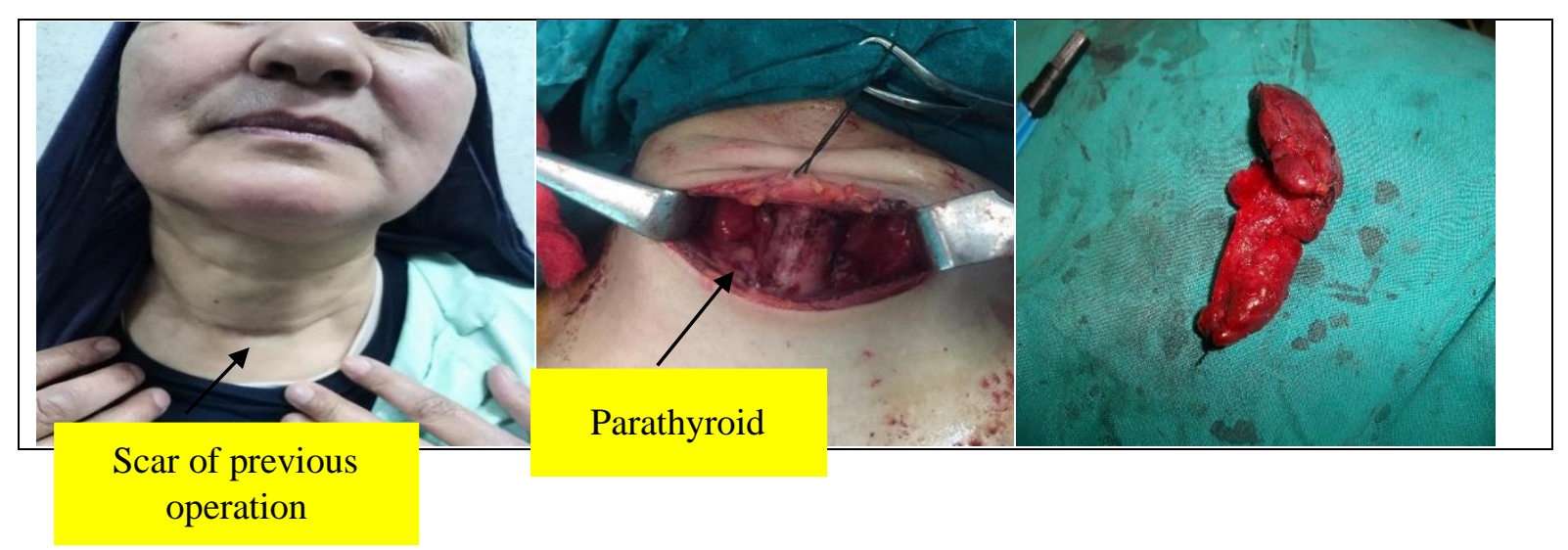

Case (4): Shows 59-year-old female patient with recurrent goiter underwent recurrent thyroidectomy late redo surgery. Bed of the removed thyroid gland showing 1. RLN 2. Parathyroid Gland (PGs), Removed specimen late redo thyroidectomy.

\section{Statistical analysis}

Recorded data were analyzed using the statistical package for the social sciences, version 20.0 (SPSS Inc., Chicago, Illinois, USA). Quantitative data were expressed as mean \pm standard deviation (SD). Qualitative data were expressed as frequency and percentage and were compared by Chi-square $\left(\mathrm{X}^{2}\right)$ test of significance. $\mathrm{P}$ value $<0.05$ was considered significant.

\section{RESULTS}

Age: The mean age was $41.43 \pm 9.27$ years. With $32(38 \%)$ patients within age of (51-75) and $52(62 \%)$ patients within age of (18-45). Sex: Males represented 6 patients (10\%) while females represented 54 patients (90\%). FNAC: Preoperative cytological examination showed $70 \%$ of our cases were benign and $30 \%$ were malignant (Table 1).

Table (1): Age, sex, and fine needle aspiration cytology of the patients among the study group

\begin{tabular}{|c|c|c|c|c|c|c|c|c|}
\hline & \multicolumn{2}{|c|}{$\begin{array}{c}\text { Total } \\
\text { Thyroidectomy } \\
(\mathbf{n}=20)\end{array}$} & \multicolumn{2}{|c|}{$\begin{array}{c}\text { Early redo } \\
\text { Thyroidectomy } \\
(\mathbf{n}=\mathbf{2 0})\end{array}$} & \multicolumn{2}{|c|}{$\begin{array}{c}\text { Late redo } \\
\text { Thyroidectomy } \\
(\mathbf{n}=\mathbf{2 0})\end{array}$} & \multirow[t]{2}{*}{$\mathbf{P}$} \\
\hline & & No & $\%$ & No & $\%$ & No & $\%$ & \\
\hline \multirow[b]{2}{*}{ Gender } & Female & 17 & $85 \%$ & 19 & $95 \%$ & 18 & $90 \%$ & \multirow[t]{2}{*}{0.212} \\
\hline & Male & 3 & $15 \%$ & 1 & $5 \%$ & 2 & $10 \%$ & \\
\hline \multirow[t]{2}{*}{ Age } & Middle (18-45) & 12 & $60 \%$ & 16 & $80 \%$ & 0 & $0 \%$ & \multirow[t]{2}{*}{0.369} \\
\hline & Old (46-73) & 8 & $40 \%$ & 4 & $20 \%$ & 20 & $100 \%$ & \\
\hline \multirow[t]{2}{*}{ FNAC } & Benign & 14 & $70 \%$ & 0 & $0 \%$ & 18 & $90 \%$ & \multirow[b]{2}{*}{0.003} \\
\hline & Malignant & 6 & $30 \%$ & 20 & $100 \%$ & 2 & $10 \%$ & \\
\hline
\end{tabular}


Table (2) shows sonographic data among the study group. There was a significant difference among the 3 groups.

Table (2): Sonographic data of cases

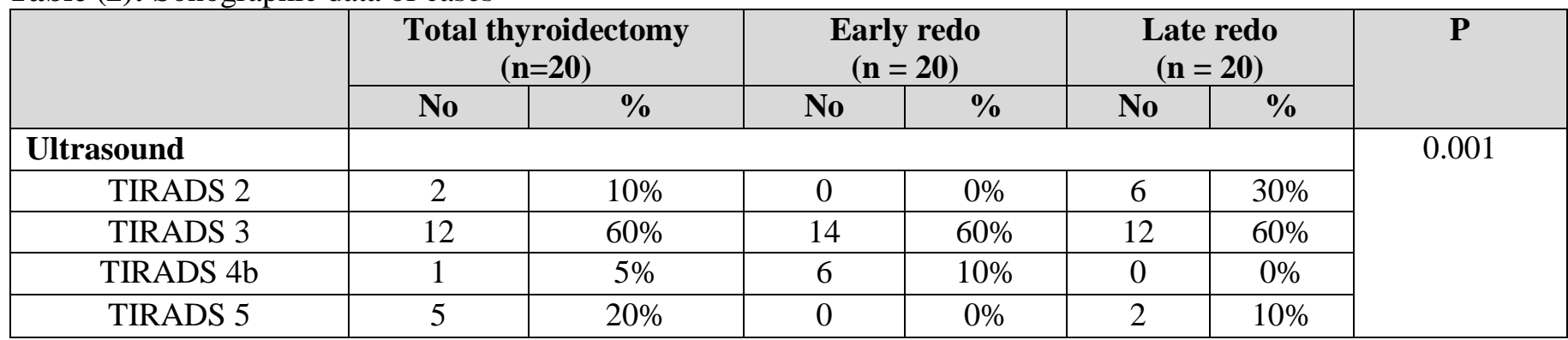

Table (3) shows that in our study 2 patients (3.3\%) of all 60 cases experienced a postoperative hematoma. Only 2 of the whole study group (3.3\%) needed to be re-explored intraoperatively, it was controlled by conservative treatment and anti-hemorrhagic drugs, and among all patients only one patient showed postoperative temporary recurrent laryngeal nerve (RLN) injury (5\%), only one patient showed signs of RLN injury at long term period in late redo surgery group.

Table (3): Postoperative hematoma, bleeding, and temporary and permanent RLN injury in our study group

\begin{tabular}{|c|c|c|c|c|c|c|c|c|}
\hline & & \multicolumn{2}{|c|}{$\begin{array}{c}\text { TT } \\
(\mathbf{n}=20)\end{array}$} & \multicolumn{2}{|c|}{$\begin{array}{c}\text { Early redo } \\
(\mathbf{n}=\mathbf{2 0})\end{array}$} & \multicolumn{2}{|c|}{$\begin{array}{c}\text { Late redo } \\
(\mathbf{n}=\mathbf{2 0})\end{array}$} & \multirow[t]{2}{*}{$\mathbf{P}$} \\
\hline & & No & $\%$ & No & $\%$ & No & $\%$ & \\
\hline \multirow{2}{*}{$\begin{array}{c}\text { Bleeding and } \\
\text { hematoma }\end{array}$} & No & 20 & $100 \%$ & 19 & $95 \%$ & 19 & $95 \%$ & \multirow[t]{2}{*}{0.002} \\
\hline & Yes & 0 & $0 \%$ & 1 & $5 \%$ & 1 & $5 \%$ & \\
\hline $\begin{array}{l}\text { RLN injury } \\
\text { temporary }\end{array}$ & Yes & 0 & $0 \%$ & 1 & $10 \%$ & 2 & $10 \%$ & \\
\hline \multirow{2}{*}{$\begin{array}{l}\text { RLN injury } \\
\text { permanent }\end{array}$} & Mobile & 20 & $100 \%$ & 20 & $100 \%$ & 19 & $95 \%$ & \multirow[t]{2}{*}{0.311} \\
\hline & Immobile & 0 & 0 & 0 & 0 & 1 & $5 \%$ & \\
\hline \multirow{3}{*}{ Scar } & Normal & 19 & $95 \%$ & 17 & $85 \%$ & 16 & $80 \%$ & \multirow[t]{3}{*}{0.365} \\
\hline & Keloid & 0 & $0 \%$ & 1 & $5 \%$ & 3 & $15 \%$ & \\
\hline & Hyperemic & 1 & $5 \%$ & 2 & $10 \%$ & 1 & $5 \%$ & \\
\hline
\end{tabular}

Table (4) shows that among the study group 4 cases (6.6\%) showed early postoperative hypocalcemic manifestations. Only one of these 4 cases (1.6\%) showed late manifestations of long-term hypocalcemia and needed medical treatment of these manifestations.

Table (4): Postoperative values of early and late hypocalcemia

\begin{tabular}{|c|c|c|c|c|c|c|c|c|}
\hline & & \multicolumn{2}{|c|}{$\begin{array}{c}\text { TT } \\
(\mathbf{n}=20)\end{array}$} & \multicolumn{2}{|c|}{$\begin{array}{c}\text { Early redo } \\
(\mathbf{n}=\mathbf{2 0})\end{array}$} & \multicolumn{2}{|c|}{$\begin{array}{l}\text { Late redo } \\
(\mathbf{n}=\mathbf{2 0})\end{array}$} & \multirow[t]{2}{*}{$\mathbf{P}$} \\
\hline & & No & $\%$ & No & $\%$ & No & $\%$ & \\
\hline \multirow[t]{2}{*}{ Hypocalcemia post 3 days } & No & 19 & $95 \%$ & 19 & $95 \%$ & 17 & $85 \%$ & \multirow[t]{2}{*}{0.305} \\
\hline & Yes & 1 & $5 \%$ & 1 & $5 \%$ & 3 & $15 \%$ & \\
\hline \multirow[t]{2}{*}{ Hypocalcemia post 3 months } & No & 20 & $100 \%$ & 20 & $100 \%$ & 19 & $95 \%$ & \multirow[t]{2}{*}{0.311} \\
\hline & Yes & 0 & $0 \%$ & 0 & $0 \%$ & 1 & $5 \%$ & \\
\hline \multirow[t]{2}{*}{ Hypocalcemia post 6 months } & No & 20 & $100 \%$ & 20 & $100 \%$ & 19 & $95 \%$ & \multirow[t]{2}{*}{0.311} \\
\hline & Yes & 0 & $0 \%$ & 0 & $0 \%$ & 1 & $5 \%$ & \\
\hline
\end{tabular}

Table (5) shows that serum TSH levels postoperatively 3 months the follow up TSH levels showed hypothyroidism in 6 cases (10\%), on follow up of the three groups of cases for TSH levels after 6 months 2 patients (3.3\%) from the (group 1 ) and (group 2) showed hypothyroidism. 
Table (5): Postoperative TSH levels follow up at $3^{\text {th }}$ and $6^{\text {th }}$ months among all the studied cases

\begin{tabular}{|c|c|c|c|c|c|c|c|c|}
\hline & & \multicolumn{2}{|c|}{$\begin{array}{c}\text { TT } \\
(n=20)\end{array}$} & \multicolumn{2}{|c|}{$\begin{array}{l}\text { Early redo } \\
(\mathbf{n}=20)\end{array}$} & \multicolumn{2}{|c|}{$\begin{array}{c}\text { Late redo } \\
(\mathbf{n}=20)\end{array}$} & \multirow[t]{2}{*}{$\mathbf{P}$} \\
\hline & & No & $\%$ & No & $\%$ & No & $\%$ & \\
\hline \multirow[t]{2}{*}{ TSH post 3 months } & Normal & 19 & $95 \%$ & 18 & $85 \%$ & 17 & $90 \%$ & \multirow[t]{2}{*}{0.633} \\
\hline & Hypothyroidism & 1 & $5 \%$ & 2 & $15 \%$ & 3 & $10 \%$ & \\
\hline \multirow[b]{2}{*}{ TSH post 6 months } & Normal & 20 & $100 \%$ & 19 & $95 \%$ & 19 & $95 \%$ & \multirow[t]{2}{*}{1.0} \\
\hline & Hypothyroidism & 0 & $0 \%$ & 1 & $5 \%$ & 1 & $5 \%$ & \\
\hline
\end{tabular}

\section{DISCUSSION}

Completion thyroidectomy can most accurately be described as re-exploration of the neck to remove the contralateral thyroid lobe. This procedure has commonly been performed when the histopathologic condition of the ipsilateral thyroid lobe reveals papillary or follicular carcinoma of the thyroid. Because of a definitely increased risk of complications with completion thyroidectomy, avoiding its routine use is important ${ }^{(6)}$. The resection of an enlarged remnant gland and reoperations in the thyroid bed are surgically challenging because of the distortion of anatomic planes and scarring from prior surgery ${ }^{(7)}$.

Abdel-Latif et al. ${ }^{(8)}$, proved, in a study of 42 patients with benign thyroid diseases underwent total thyroidectomy with one year follow up, that the total thyroidectomy (TT) gives better results in management of patients with benign thyroid diseases compared to near total thyroidectomy (NTT) . Total thyroidectomy (TT) is advised to be done in patients with benign thyroid diseases because there is no recurrence postoperatively, provided to be done by experienced endocrine surgeon in a qualified center. Also Accetta $e t$ al. ${ }^{(9)}$ mentioned that total thyroidectomy is an operation that can be performed safely, with a low incidence of permanent complications, thus avoiding future recurrences and reoperations.

The present study we carried out as a comparative controlled study on 60 patients who underwent primary total thyroidectomy, early and late redo in thyroid surgeries over a period of one year. 20 patients who underwent primary total thyroidectomy in group (1), 20 patients who underwent completion thyroidectomy in group of early redo in thyroid surgeries and another 20 patients underwent recurrent total thyroidectomy of group of late redo in thyroid surgeries (recurrent thyroidectomy). In our study we aimed to determine the effect, difficulties and complications of early and late redo in thyroid surgeries for two groups mentioned regarding postoperative TSH levels and calcium over 3 months, 6 months, one year and the other short term postoperative complications as (RLN injury, transient hypocalcaemia, hematoma, and postoperative bleeding). Among the 60 patients there were 6 males $(10 \%)$ and 54 females.

In our study, we found our final pathology examinations in group (1) of total thyroidectomy that there were 14 specimens with benign colloid and 6 specimens with papillary thyroid carcinoma (PTC), early redo in thyroid surgeries were benign colloid for 14 specimens, PTC for 4 specimens, follicular thyroid carcinoma (FTC) for 2 specimens but in group of late redo in thyroid surgeries we found benign colloid for 18 specimens and PTC for 2 specimens. These results showed that remnant thyroid after subtotal resection might cause malignant progression in some patients after a long period of time. The remnant tissue harboring the malignant lesion should be excised by redo surgery. Gibelin et al. ${ }^{(10)}$ have reported that surgery for recurrent nodular goiter is associated with a significant risk of RLN morbidity.

Promberger et al. (11) mentioned that the incidence of bleeding after thyroid gland surgery varies from $0 \%$ to $4.2 \%$. According to the available literature. Also Godballe et al. ${ }^{(12)}$ mentioned that the rate is related to a given center's experience, as shown in a Dutch study in which the frequency of bleeding ranged from $1.9 \%$ to $14.3 \%$ in different hospitals, but Rosenbaum et al. (13) mentioned that in highly experienced departments the rate usually does not exceed $1 \%$. In our study, we found that about $2.5 \%$ (2 cases) had bleeding and hematoma post early and late redo in thyroid surgeries (a case in each group), so we had treated them in operative room and controlled the bleeding.

In our study, Post 3 day of early and late redo in thyroid surgeries thyroidectomy, hypocalcaemia manifestations were only in 4 cases of 40 cases, (5\% of group 1) and (15\% of group 2). After 3 months of follow up there were 2 cases with hypocalcaemia. There was a case with hypocalcemic manifestations post 6 months with history that he neglected tablets many times so we completed follow up and medical treatment of calcium and vitamin $\mathrm{D}$ tables supplements and he improved on medical treatment post 1 year. Lombardi et al. (14) reported a worse score for tissue adhesive, with respect to subcuticular suture or metal clips. In our study, we found that 4 cases of 40 cases, about (10\%) had keloid scar and another 3 cases (7.5\%) with hyperemic scar post recurrent thyroidectomy. In our result, we found 4 cases had hypothyroidism post 6 months and with follow up on eltroxin oral tablet became only 2 cases had hypothyroidism post 1 year with history of 
forgetting the dose many times and there was no wound infection.

\section{CONCLUSION}

Total thyroidectomy is advised to be done in all patients with thyroid diseases as there were no recurrence detected and to avoid complications that may be present in re do surgery. To guard against performance of completion thyroidectomy, ultrasound examination and FNAC should be taken from different sites.

Financial support and sponsorship: Nil.

Conflict of interest: Nil.

\section{REFERENCES}

1. Bellantone $\mathrm{R}$, Lombardi $\mathrm{C}$, Boscherini $\mathrm{M}$ et al. (2004): Predictive factors for recurrence after thyroid lobectomy for unilateral non-toxic goiter in an endemic area: results of a multivariate analysis. Surgery, 136: 1247-1251.

2. Sturgeon C, Angelos P (2006): Identification and treatment of aggressive thyroid cancers. Part 2: risk assessment and treatment. Oncology, 20: 397-404.

3. Lefevre J, Tresallet C, Leenhardt L et al. (2007): Reoperative surgery for thyroid disease. Langenbecks Arch Surg., 392: 685-691.

4. Alvarado R, Sywak M, Delbridge L et al. (2009): Central lymph node dissection as a secondary procedure for papillary thyroid cancer: Is there added morbidity? Surgery, 145: 514-51.
5. Snook K, Stalberg P, Sidhu S et al. (2007): Recurrence after total thyroidectomy for benign multinodular goiter. World J Surg., 31: 593-59.

6. Bilimoria K, Zanocco K, Sturgeon C (2008): Impact of surgical treatment on outcomes for papillary thyroid cancer. Adv Surg., 42: 1-12.

7. Richer L, Wenig B (2008): Changes in surgical anatomy following thyroidectomy. Otolaryngologic Clinics of North America, 41: 1069-1078.

8. Abdel-Latif A, Elsayed Y, Gado W et al. (2020): Total versus near total thyroidectomy in treatment of toxic Goiter. The Egyptian Journal of Hospital Medicine, 78(2): 317-321.

9. Accetta P, Accetta I, Accetta A et al. (2011): Total thyroidectomy for benign thyroid diseases. Revista do CBC., 38: 223-226.

10. Gibelin H, Sierra M, Mothes D et al. (2004): Risk factors for recurrent nodular goiter after thyroidectomy for benign disease: Case-control study of 244 patients. World Journal of Surgery, 28: 1079-1082.

11. Promberger R, Ott J, Kober F et al. (2012): Risk factors for postoperative bleeding after thyroid surgery. Br J Surg., 99:373-9.

12. Godballe C, Madsen A, Pedersen H et al. (2009): Post-thyroidectomy hemorrhage: a national study of patients treated at the Danish Departments of ENT Head and Neck Surgery. Eur Arch Othorhinolaryngol., 266:1945-52.

13. Rosenbaum M, Haridas M, McHenry C (2008): Lifethreatening neck hematoma complicating thyroid and parathyroid surgery. Am J Surg., 195:339-43.

14. Lombardi P, Bracaglia R, Revelli L et al. (2011): Aesthetic result of thyroidectomy: Evaluation of different kinds of skin suture. Annali Italiani di Chirurgia, 82(6):449-55. 